\title{
Normas para la protección de niños ante la pandemia COVID-19
}

\section{Guidelines for the protection of children against the COVID-19 pandemic}

Roberto Guillermo Calva-y Rodríguez,*,+ Alicia Robledo-Galván,* Alfredo Vigueras-Rendón,* Guillermo Yanowsky-Reyes, ${ }^{*}$ Francisco Paredes-Fernández,* Manuel Gil-Vargas,* Reynaldo Michel-Aceves ${ }^{\ddagger}$

* Mesa Directiva; ${ }^{\ddagger}$ Coordinador Departamento de Pediatría Social Preventiva, Academia Mexicana de Pediatría, $2019-2021$.

La Academia Mexicana de Pediatría, a través de la Mesa Directiva y el Departamento de Pediatría Social y Preventiva, presenta a la sociedad sus recomendaciones para la protección de niños ante la pandemia de COVID-19:

Normas para proteger niños menores de dos años:

- Cubra el portabebé y carreola con una manta de tela.

- Mantenga la distancia adecuada entre niños y adultos.

- No le ponga cubrebocas, puede tener consecuencias a su salud.

- Si hay personas cerca, tape con una frazada toda su cabecita.

Normas para proteger niños mayores de dos años:

- Colóquele cubrebocas cuando salga de casa.
- Póngale cubrebocas dentro de casa, cuando alguna persona esté enferma, o en caso de que padezca alguna enfermedad inmunológica.

- Mantenga la distancia adecuada entre niños y adultos.

- Si el niño utiliza cubrebocas, los padres también deben emplearlo.

- En lo posible, adorne el cubrebocas con figuras o diseños.

- A sus juguetes póngales cubrebocas también.

- Enséñele a lavarse las manos con frecuencia.

- Si puede, llévelo a realizar actividades al aire libre, incluso sólo caminar.

- Mantenga hábitos de alimentación saludable.

- Practique los juegos y la lectura en familia.

- Limpie y desinfecte con frecuencia las superficies que el niño(a) toca.

- Lave sus juguetes con frecuencia con agua y jabón.

- Evite visitar a otros familiares como padres, abuelos, etcétera.

\section{WWW.medigraphic.org.nx}

\footnotetext{
+Correspondencia: RGCR, dr.robertocalvarodriguez@gmail.com Conflicto de intereses: Los autores declaran que no tienen.

Citar como: Calva-y Rodríguez RG, Robledo-Galván A, Vigueras-Rendón A, Yanowsky-Reyes G, Paredes-Fernández F, Gil-Vargas M et al. Normas para la protección de niños ante la pandemia COVID-19. Rev Mex Pediatr. 2020; 87(4): 158. https://dx.doi.org/10.35366/95828
} 